\title{
Phylogenetic analysis of the genus Aeromonas based on two housekeeping genes
}

Correspondence

A. J. Martínez-Murcia ammurcia@mdc-bt.com
L. Soler, ${ }^{3} \dagger$ M. A. Yáñez, ${ }^{2,4} \uparrow$ M. R. Chacon, ${ }^{3}$ M. G. Aguilera-Arreola, ${ }^{3,5}$ V. Catalán, ${ }^{4}$ M. J. Figueras ${ }^{3}$ and A. J. Martínez-Murcia ${ }^{1,2}$

\author{
${ }^{1}$ Molecular Diagnostics Center, Ctra Ncnal, 340, Km 29 Aptdo, 169, E-03300 Orihuela \\ (Alicante), Spain \\ 2Departamento de Microbiología, Universidad Miguel Hernández, Ctra Beniel Km 3, \\ E-03312 Orihuela (Alicante), Spain \\ 3Unidad de Microbiología, Departamento de Ciencias Médicas Básicas, Facultad de Medicina y \\ Ciencias de la Salud, Universidad Rovira y Virgili, Reus, E-43201 Tarragona, Spain \\ ${ }^{4}$ Labaqua, S.A., Alona, 33, E-03007 Alicante, Spain \\ ${ }^{5}$ Departamento de Microbiología, Escuela Nacional de Ciencias Biológicas, Instituto Politécnico \\ Nacional, 11340 México Distrito Federal, Mexico
}

\begin{abstract}
The phylogenetic relationships of all known species of the genus Aeromonas, and especially Aeromonas bestiarum and Aeromonas salmonicida, were investigated on 70 strains using the $r p o D$ sequence, which encodes the $\sigma^{70}$ factor. This analysis was complemented with the sequence of $g y r B$, which has already proven useful for determining the phylogenetic relationships in the genus. Nucleotide sequences of $r p o D$ and gyrB showed that both genes had similar substitution rates $(<2 \%$ ) and a similar number of variable positions (34\% for $r p o D$ versus $32 \%$ for $g y r B$ ). Strain groupings by analysis of $r p o D$, gyrB and a combination of both genes were consistent with the taxonomic organization of all Aeromonas species described to date. However, the simultaneous analysis of both clocks improved the reliability and the power to differentiate, in particular, closely related taxa. At the inter-species level, gyrB showed a better resolution for differentiating Aeromonas sp. HG11/Aeromonas encheleia and Aeromonas veroniilAeromonas culicicolalAeromonas allosaccharophila, while $r p o D$ more clearly differentiated $A$. salmonicida from $A$. bestiarum. The analysis of $r p o D$ provided initial evidence for clear phylogenetic divergence between the latter two species.
\end{abstract}

\section{INTRODUCTION}

The taxonomy of the genus Aeromonas is complex. During the last two decades, the number of new species descriptions has progressively increased, resulting in the following recognized species: Aeromonas hydrophila, Aeromonas bestiarum, Aeromonas salmonicida, Aeromonas caviae, Aeromonas media, Aeromonas eucrenophila, Aeromonas sobria, Aeromonas veronii (biogroups sobria and veronii), Aeromonas jandaei,

Published online ahead of print on 27 February 2004 as DOI 10.1099/ ijs.0.03048-0.

†These authors made equal contributions to this work and share first authorship.

\section{Abbreviation: HG, homology group.}

The GenBank/EMBL/DDBJ accession numbers for the gyrB and rpoD sequences determined in this study are given in Fig. 1.

A matrix table showing nucleotide substitution rates in gyrB and $r p o D$ sequences is available as supplementary material in IJSEM Online.
Aeromonas schubertii, Aeromonas trota, Aeromonas allosaccharophila, Aeromonas encheleia and Aeromonas popoffii. The two DNA homology groups (HGs), Aeromonas sp. (HG11), Aeromonas sp. (HG13; formerly Enteric Group 501), remain without a species name. The new species Aeromonas culicicola was described recently (Pidiyar et al., 2002). The species Aeromonas enteropelogenes (Schubert et al., 1990a) and Aeromonas ichthiosmia (Schubert et al., $1990 \mathrm{~b})$ are now considered to be synonyms of $A$. trota and A. veronii, respectively (Carnahan, 1993; Collins et al., 1993; Huys et al., 2001, 2002).

One of the controversial taxonomic issues is represented by the species $A$. hydrophila, type species of the genus, and related species $A$. bestiarum and A. salmonicida, all of them included in the so-called 'A. hydrophila' complex (Janda \& Abbott, 1998). A. salmonicida includes four psychrophilic non-motile subspecies: A. salmonicida subsp. salmonicida (Griffin et al., 1953), A. salmonicida subsp. achromogenes (Smith, 1963), A. salmonicida subsp. masoucida (Kimura, 
1969a, b) and A. salmonicida subsp. smithia (Austin et al., 1989); and the mesophilic subspecies A. salmonicida subsp. pectinolytica (Pavan et al., 2000). In addition, A. salmonicida includes motile mesophilic strains confusingly referred to as 'A. hydrophila' (HG3) (Altwegg et al., 1990). A lack of phenotypic and genotypic criteria to split $A$. bestiarum from A. salmonicida has been found (Martínez-Murcia and co-workers, unpublished data). Moreover, a phylogenetic analysis using gyrB sequences confirmed a very close relationship between the two clusters corresponding to $A$. bestiarum and $A$. salmonicida, but definitive conclusions could not be taken as the range of nucleotide substitutions was borderline of that observed for other Aeromonas species (Yáñez et al., 2003).

The study of two or more housekeeping genes could be useful to improve the reliability of the phylogenies (Stackebrandt et al., 2002; Yamamoto \& Harayama, 1998). It has been reported that $g y r B$ (encoding the B-subunit of DNA gyrase, a type II DNA topoisomerase) and $r p o D$ (encoding $\sigma^{70}$ factor which is one of the sigma factors that confer promoter-specific transcription initiation on RNA polymerase) could be suitable phylogenetic markers for bacterial systematics (Gruber \& Bryant, 1997; Huang, 1996; Kim et al., 1999; Watanabe et al., 2001; Yamamoto et al., 2000). They seem to be good index genes for determining the course of genome evolution because they are essential single-copy genes on which horizontal genes transfer seldom occurs (Sawada et al., 1999). Recently, Yáñez et al. (2003) demonstrated that the gyrB sequence is an excellent molecular chronometer for phylogenetic inference in the genus Aeromonas, but only 17 strains corresponding to species of the 'A. hydrophila' complex were included. To our knowledge, no data are available about the phylogenetic usefulness of the $r p o D$ sequence in the genus Aeromonas.

In the present study, nucleotide sequences of gyrB and $r p o D$ genes were determined from a collection of 70 Aeromonas strains that includes all described species and DNA HGs. Derived phylogenetic analyses were inferred to investigate the Aeromonas inter-species relationships, in particular between $A$. salmonicida and A. bestiarum. Two genes and more strains were used to assess the congruence with previous gyrB phylogeny and results of $16 \mathrm{~S}$ rRNA gene sequencing and DNA-DNA pairing studies.

\section{METHODS}

Bacterial strains, culture conditions and 16S rRNA identification. A total of 70 strains comprising all known Aeromonas species were examined in this study (Table 1). New isolates and reference strains from culture collections were identified by $16 \mathrm{~S}$ rRNA gene-RFLP (Figueras et al., 2000) and further sequencing (Martínez-Murcia et al., 1999). Bacterial strains were grown on tryptic soy agar (Difco) at $28{ }^{\circ} \mathrm{C}$ with the exception of those belonging to the psychrophilic species A. salmonicida which were grown at room temperature.

DNA extraction and purification. A single colony from fresh cultures was resuspended in $50 \mu \mathrm{l}$, vortexed at high speed for
$1 \mathrm{~min}$, and incubated at $96^{\circ} \mathrm{C}$ for $10 \mathrm{~min}$. The tube was again vortexed and centrifuged for $2 \mathrm{~min}$ at $12000 \mathrm{~g}$. The supernatant was transferred to a fresh tube and stored at $-20^{\circ} \mathrm{C}$.

PCR amplification and sequencing of gyrB and rpoD. A fragment of approximately $1100 \mathrm{bp}$ of the gyrB gene was amplified by PCR and sequenced as described previously (Yáñez et al., 2003). PCR amplification for the $r p o D$ gene (fragment of approx. $820 \mathrm{bp}$ ) was performed in a Gene-AMP (PCR System Perkin Elmer 2400). A final PCR volume of $100 \mu \mathrm{l}$ contained $1 \mu \mathrm{g}$ genomic DNA, $20 \mathrm{mM}$ Tris/ $\mathrm{HCl} \mathrm{pH} 8 \cdot 4,50 \mathrm{mM} \mathrm{KCl}, 3 \mathrm{mM} \mathrm{MgCl}, 0 \cdot 3 \mathrm{mM}$ dNTPs, $2.5 \mathrm{U}$ Taq DNA polymerase (Invitrogen) and $1 \mu \mathrm{M}$ each primer. The reaction mixture was subjected to a touch-down PCR regimen of: denaturation at $95^{\circ} \mathrm{C}$ for $5 \mathrm{~min}$, followed by 2 cycles at $94{ }^{\circ} \mathrm{C}$ for $1 \mathrm{~min}$ (denaturation); $63^{\circ} \mathrm{C}$ for $1 \mathrm{~min}$ (annealing); $72^{\circ} \mathrm{C}$ for $1 \mathrm{~min}$ (extension); 2 cycles at $94^{\circ} \mathrm{C}, 1 \mathrm{~min} ; 61^{\circ} \mathrm{C}, 1 \mathrm{~min} ; 72^{\circ} \mathrm{C}, 1 \mathrm{~min}$; 2 cycles at $94^{\circ} \mathrm{C}, 1 \mathrm{~min} ; 59^{\circ} \mathrm{C}, 1 \mathrm{~min} ; 72^{\circ} \mathrm{C}, 1 \mathrm{~min}$; and 30 cycles at $94{ }^{\circ} \mathrm{C}, 1 \mathrm{~min} ; 58^{\circ} \mathrm{C}, 1 \mathrm{~min} ; 72^{\circ} \mathrm{C}, 1 \mathrm{~min}$. Amplified products were electrophoresed on $0 \cdot 8 \%$ agarose/TBE gels, and purified using the GFX PCR DNA and Gel Band Purification Kit (Amersham Pharmacia Biotech). Nucleotide sequences were determined by using the ABI PRISM BigDye Terminators v2.0 Cycle Sequencing Kit in the ABI PRISM 310 Genetic Analyzer (Applied Biosystems) according to the manufacturer's instructions. Characteristics of primers used for PCR amplification and sequencing of $g y r B$ and $r p o D$ are summarized in Table 2 .

Phylogenetic data analysis. The nucleotide sequences of $\operatorname{gyr} B$ and $r p o D$ were independently aligned by the CLUSTAL_X program, version 1.8 (Thompson et al., 1997). Genetic distances were obtained using Kimura's 2-parameter model (Kimura, 1980) and evolutionary trees were constructed by the neighbour-joining method (Saitou \& Nei, 1987) with the MEGA program (Kumar et al., 2001). A gyrB$r p o D$ phylogenetic tree was also constructed from the combination of these two genes and treating it as a single nucleotide sequence (Yamamoto et al., 2000).

\section{RESULTS AND DISCUSSION}

In the present study, nucleotide sequences of $g y r B$ and $r p o D$ amplicons were determined from 26 and 68 Aeromonas strains, respectively (Table 1 ). The other gyrB sequences were published previously in a phylogenetic study of the genus Aeromonas (Yáñez et al., 2003). Experiments were repeated at least twice from single colonies of original cultures to confirm readings and solve ambiguities. The derived gyrB sequences comprised between 960 and 1100 nucleotides covering more than $70 \%$ of the ATPase domain (amino acid residues 2-392 in Escherichia coli; Huang, 1996) and 191 nucleotides of the $3^{\prime}$ flanking region. The rpoD sequences comprised between 813 and 825 nucleotides covering approximately $46 \%$ of the protein (amino acid residues 112-369 in E. coli; Barne et al., 1997); however, the active domain is not included in this stretch. Identification of species by $16 \mathrm{~S}$ rRNA gene sequencing is shown in Table 1.

\section{Comparative analysis of gyrB and $r p o D$ sequence alignments}

The gyrB sequences from all aeromonads were aligned and percentages of nucleotide substitutions were calculated for a continuous stretch of 957 bases (positions 404-1364 
Table 1. Aeromonas strains used in this study

DNA homology groups are given in parentheses. Culture collections: ATCC, American Type Culture Collection, Manassas, VA, USA; CCUG, Culture Collection of the University Göteborg, Göteborg, Sweden; CDC, Centers for Disease Control and Prevention, Atlanta, GA, USA; CECT, Colección Española de Cultivos Tipo, Universidad de Valencia, Valencia, Spain; CIP, Collection bactérienne de l'Institut Pasteur, Paris, France; DSMZ, Deutsche Sammlung von Mikroorganismen und Zelkulturen, Braunschweig, Germany; LMG, Culture Collection of the Laboratorium voor Microbiologie Gent, Universiteit Gent, Ghent, Belgium; NCIMB, National Collection of Industrial and Marine Bacteria, Aberdeen, UK.

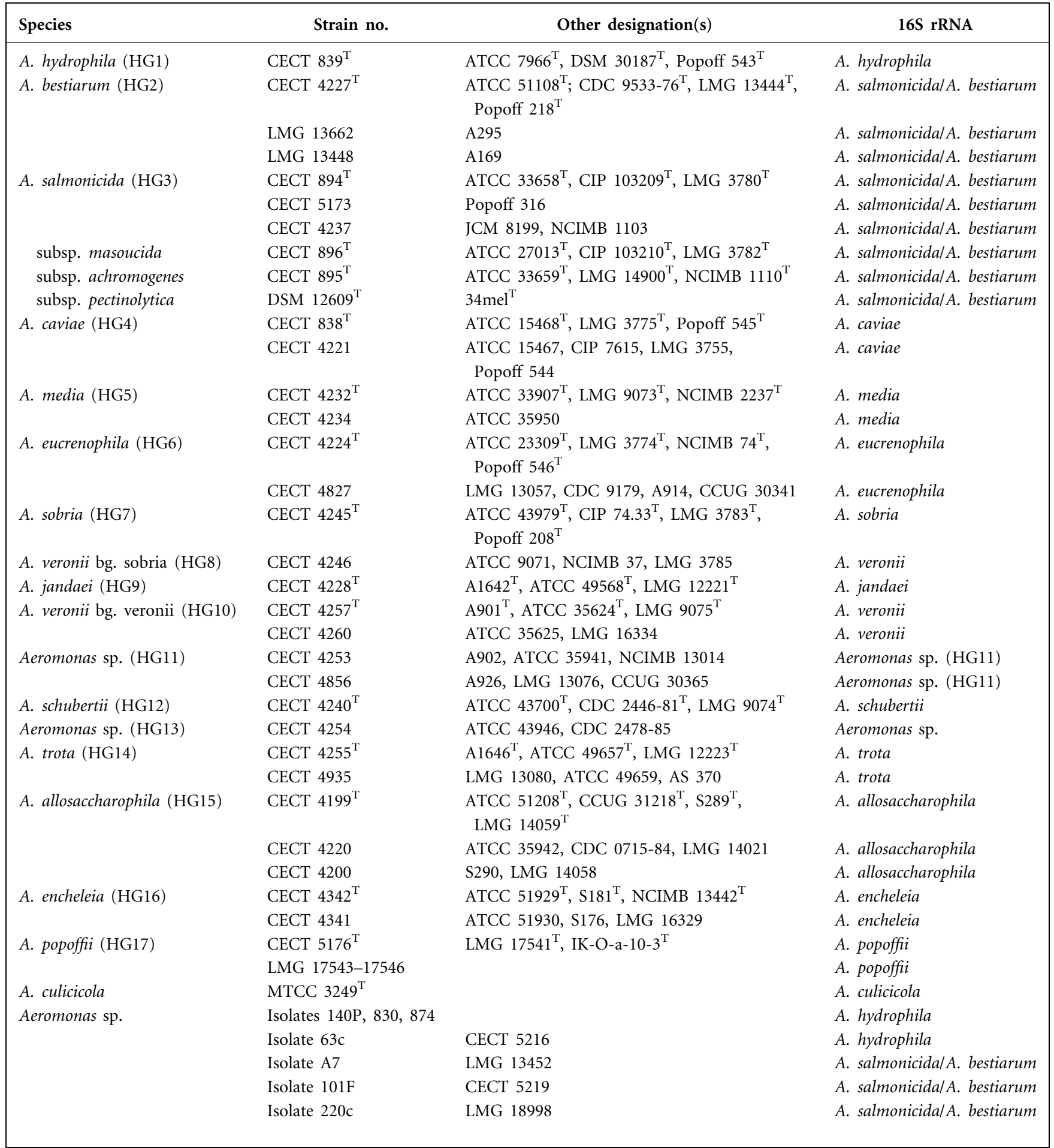


Table 1. cont.

\begin{tabular}{|c|c|c|c|}
\hline Species & Strain no. & Other designation(s) & 16S rRNA \\
\hline & Isolate $665 c$ & & A. caviae \\
\hline & Isolate $239,480,280,610,57$ & & Aeromonas sp. \\
\hline & Isolate 350 & & A. sobria \\
\hline & Isolate 344 & & A. jandaei \\
\hline
\end{tabular}

according to E. coli numbering). Ranges of inter-species nucleotide substitution rates were determined (available as supplementary material in IJSEM Online) by taking the maximum and minimum divergence values obtained when comparing each single species (including all isolates) with all strains of all other Aeromonas species. Sequence similarity between all Aeromonas strains was 86.3-100\%, corresponding to $0-131$ nucleotide differences. Number of total variable positions was 306 (approx. $32 \%$ of the determined fragment) in addition to insertion/deletion of a single triplet. At the intra-species level, the rates of nucleotide substitutions were $0-2 \cdot 3 \%$, often showing values under $2 \%$, with an overall value of approximately $1 \cdot 6 \%$. However, inter-species nucleotide substitutions were usually over $3 \%$, except for the following two pairs of species: $A$. salmonicida and $A$. bestiarum $(1 \cdot 8-4 \cdot 3 \%)$, and $A$. encheleia and Aeromonas sp. HG11 $(2 \cdot 1-2 \cdot 2 \%)$.

The $r p o D$ sequences from all aeromonad strains were aligned and percentage nucleotide substitutions (Table A in IJSEM Online) were calculated for a continuous stretch of 813 bases (ranging from positions 332-1108 according to
E. coli numbering). Sequence similarity between all Aeromonas strains was $81 \cdot 7-100 \%$, corresponding to $1-148$ nucleotide differences. The alignment exhibited a total of 281 variable positions (approx. 34\% of the fragment sequenced) and number of insertions/deletions was $12 \mathrm{bp}$, corresponding to 4 codons. At the intra-species level, the rates of nucleotide substitutions were $0-2 \cdot 6 \%$, being under $2 \%$ for most Aeromonas species, and overall value of approximately $1 \cdot 6 \%$. Inter-species nucleotide substitution was over $3 \%$ except for the following pairs of species: A. encheleia/Aeromonas sp. HG11 $(1 \cdot 4-1 \cdot 7 \%)$ and $A$. veronii/A. culicicola $(1 \cdot 6-1 \cdot 7 \%)$.

The comparison of $g y r B$ and $r p o D$ data indicated that both genes show similar substitution rates. The number of variable positions is not very different $(32 \%$ for $g y r B$ versus $34 \%$ for $r p o D$ ) and the ranges of nucleotide mutations between all strains are also almost the same (0-131 and 0-148, respectively). It has to be considered that $70 \%$ of determined gyrB fragment corresponded to the ATPase domain while the $r p o D$ fragment did not contain the protein active-site (Lonetto et al., 1992).

Table 2. Primers used for PCR amplification and sequencing of $g y r B$ and $r p o D$ genes

\begin{tabular}{|c|c|c|c|}
\hline Primer & Position $^{\star}$ & Sequence $\left(5^{\prime} \rightarrow 3^{\prime}\right) \dagger$ & Reference \\
\hline \multicolumn{4}{|l|}{$\operatorname{gyr} B$} \\
\hline gyrB 3F & $334-354$ & TCCGGCGGTCTGCACGGCGT & Yáñez et al. (2003) \\
\hline gyrB 9Rs & $980-960$ & CCTTGACCGAAATGACCGCC & Yáñez et al. (2003) \\
\hline gyrB 7F & $792-812$ & GGGGTCTACTGCTTCACCAA & Yáñez et al. (2003) \\
\hline gyrB 9R & $979-959$ & ACCTTGACGGAGATAACGGC & Yáñez et al. (2003) \\
\hline gyrB $14 \mathrm{R}$ & $1464-1444$ & TTGTCCGGGTTGTACTCGTC & Yáñez et al. (2003) \\
\hline \multicolumn{4}{|l|}{ rpoD } \\
\hline rpoD $70 \mathrm{~F}$ & $280-323$ & ACGACTGACCCGGTACGCATGTAYATGMGNGARATGGGNACNGT & Yamamoto et al. (2000) \\
\hline rpoD 70Fs & $280-302$ & ACGACTGACCCGGTACGCATGTA & Yamamoto et al. (2000) \\
\hline rpoD 70Fs1 & $740-757$ & GTCAATTCCGCCTGATGC & This study \\
\hline rpoD 70R & $1139-1096$ & ATAGAAATAACCAGACGTAAGTTNGCYTCNACCATYTCYTTYTT & Yamamoto et al. (2000) \\
\hline rpoD 70Rs & $1139-1117$ & ATAGAAATAACCAGACGTAAGTT & Yamamoto et al. (2000) \\
\hline rpoD 70Rs1 & $800-782$ & ATCATCTCGCGCATGTTGT & This study \\
\hline
\end{tabular}

${ }^{\star}$ Positions according to E. coli numbering.

$\dagger$ Symbols: $\mathrm{N}=$ any nucleotide; $\mathrm{R}=\mathrm{A}$ or $\mathrm{G} ; \mathrm{S}=\mathrm{C}$ or $\mathrm{G} ; \mathrm{Y}=\mathrm{C}$ or $\mathrm{T} ; \mathrm{M}=\mathrm{A}$ or $\mathrm{C}$. 
At the intra-species level, substitution rates are very similar: $0-2 \cdot 3 \%$ for $g y r B, 0-2 \cdot 6 \%$ for $r p o D$ and around $1.6 \%$ in both gene sequences. Identical $r p o D$ and gyrB sequences were found for A. media strains CECT 4234 and CECT $4232^{\mathrm{T}}$ and also for A. allosaccharophila strains CECT 4200 and CECT $4199^{\mathrm{T}}$. However, while identical $r p o D$ sequences were found in A. encheleia strains CECT 4341 and CECT $4342^{\mathrm{T}}$, and also for A. eucrenophila CECT 4827 and CECT $4224^{\mathrm{T}}$, the corresponding $\operatorname{gyr} B$ sequences determined in a previous work (Yáñez et al., 2003) showed 2 and 8 nucleotide differences, respectively. Therefore, we repeated the sequencing of both genes for the above strains, starting from fresh cultures, and concluded that these pairs of strains contain identical $r p o D$ and $g y r B$ sequences. The finding of perfect matches in two different markers in four cases suggests that these pairs may be strain duplicates. Identical genetic profiles obtained for the respective pairs of strains by using ERIC and REP-PCR typing methods reinforced this possibility (data not shown).

At the inter-species level, however, the two phylogenetic markers behaved differently and depending on the species. Between Aeromonas species, the ranges of nucleotide substitution rates for $r p o D$ were notably higher (very often almost double) than those of $\operatorname{gyrB}$ (see Table A in IJSEM Online). But, two pairs of species, A. encheleia/Aeromonas sp. HG11 $(2 \cdot 1-2 \cdot 2 \%, g y r B ; 1 \cdot 4-1 \cdot 7 \%, r p o D)$ and A. veroniil A. culicicola $(3 \cdot 5-3 \cdot 7 \%, \operatorname{gyrB} ; 1 \cdot 6-1 \cdot 7 \%, r p o D)$, were exceptions. An example of this higher inter-species mutation rate exhibited by rpoD is A. salmonicida/A. bestiarum with a range of $1 \cdot 8-4 \cdot 3 \%$ for $g y r B$, but $6 \cdot 8-8 \cdot 7 \%$ for the rpoD sequence (see Table A in IJSEM Online).

In conclusion, in Aeromonas species, $r p o D$ showed a better inter-species resolution to split $A$. salmonicida from $A$. bestiarum; however, gyrB was better for differentiating Aeromonas sp. HG11/A. encheleia and A. veronii/A. culicicola/A. allosaccharophila.

\section{Phylogenetic relationships of Aeromonas spp.}

Unrooted phylogenetic trees for $g y r B$ (Fig. 1a), $r p o D$ (Fig. 1b) and the combined gyrB-rpoD gene sequences (1770 bp; Fig. 1c) were constructed from the derived genetic matrices. All obtained phylogenies showed considerable divergence (branch lengths) between all Aeromonas species under study. Strain grouping was consistent in all three trees in agreement with a recently published phylogenetic study based on gyrB (Yáñez et al., 2003). Some differences were observed in the topology at the deepest branching points of single gyrB and $r p o D$ trees (Fig. 1a, b). This reflected the differences in the inter-species nucleotide substitution rates between $\operatorname{gyr} B$ and $r p o D$ sequences and, as a consequence, lower bootstrap values appeared at the deepest branching points of the combined gyrB-rpoD tree (Fig. 1c). Because $r p o D$ yielded a better resolution than gyrB for splitting A. salmonicida from A. bestiarum, and the opposite was found for other closely related species (viz. $A$. encheleia/Aeromonas sp. HG11 or A. veronii/A. culicicola), the phylogeny of the genus Aeromonas was expected to be improved by constructing the $g y r B-r p o D$ tree, as it comprised the combined capacities of both molecular clocks. The study of several housekeeping gene sequences has already been recommended for improving the reliability of phylogenetic inference (Stackebrandt et al., 2002).

Addition of $r p o D$ analysis to the systematics of the genus Aeromonas has increased the advantages found previously on the basis of gyrB sequences (Yáñez et al., 2003), compared to the reference 16S rRNA gene phylogeny (MartínezMurcia et al., 1992; Martínez-Murcia, 1999). Examples of that were the pairs of species A. trotalA. caviae, A. hydrophila/A. media and A. culicicola/A. jandaei, which show only 1,3 and 1 nucleotide differences, respectively, in their $16 \mathrm{~S}$ rRNA gene sequences, but were clearly separated by gyrB sequences $(7 \cdot 3,6 \cdot 5$ and $6 \cdot 3 \%$, respectively) and even more by $r p o D(9 \cdot 8,9 \cdot 7$ and $7 \cdot 2 \%)$. Agreements between $\operatorname{grr} B$ and $16 \mathrm{~S}$ rRNA (Yáñez et al., 2003) were here confirmed, but also improved by the results obtained in the $g y r B-r p o D$ inference. For instance, A. schubertii clustered at the deepest branch of the genus, and A. veronii biogroup sobria (HG8) and $A$. veronii biogroup veronii (HG10) represented two heterogeneous phenotypes of a single species. The phylogenetic distinctiveness of $A$. allosaccharophila and $A$. veronii was greater for $\operatorname{gyrB}$ sequences $(3 \cdot 3-4 \cdot 0 \%)$; however, although very closely related by $r p o D$, the range of nucleotide substitution rates $(2 \cdot 6-3 \cdot 2 \%)$ was greater than the observed overall value (under $2 \%$ ) for considering them to be the same species. However, A. culicicola and A. veronii showed a range of $r p o D$ mutation rates of $1 \cdot 6-1 \cdot 7 \%$, which is borderline to the more likely intra-species value observed in the present analysis (approx. 1.6\%). One of the most controversial taxonomic issues is currently represented by the species A. encheleia and Aeromonas sp. HG11 (Huys et al., 1997; Martínez-Murcia, 1999; Yáñez et al., 2003). Divergence determined by gyrB was over $2 \%$, but $r p o D$ differences between these groups of strains were $1.4-$ $1 \cdot 7 \%$. This result could be considered critical as the overall analysis of the genus Aeromonas indicated that these values fall within the limits for considering these strains to be a single species. Nevertheless, only two strains for each group (HG11 and A. encheleia) have been subjected to $r p o D$ sequencing. We recommend the analysis of several housekeeping genes to investigate if any considerable phylogenetic divergence can be detected between these micro-organisms.

In the study of Yáñez et al. (2003), a group of isolates (531c, 610 and 520) showed a considerable gyrB relationship to the cluster corresponding to A. media, but exhibited substitution rates of $2 \cdot 7-3 \cdot 1 \%$. As reported, these strains showed 2-9 nucleotide differences in their 16S rRNA gene sequences compared to that of the A. media type strain; but all these mutations were located at a hypervariable stem-loop (positions 457-476), a region considered to be unreliable for making phylogenetic conclusions. This nucleotide diversity may be detected by $16 \mathrm{~S}$ rRNA gene-RFLP as 

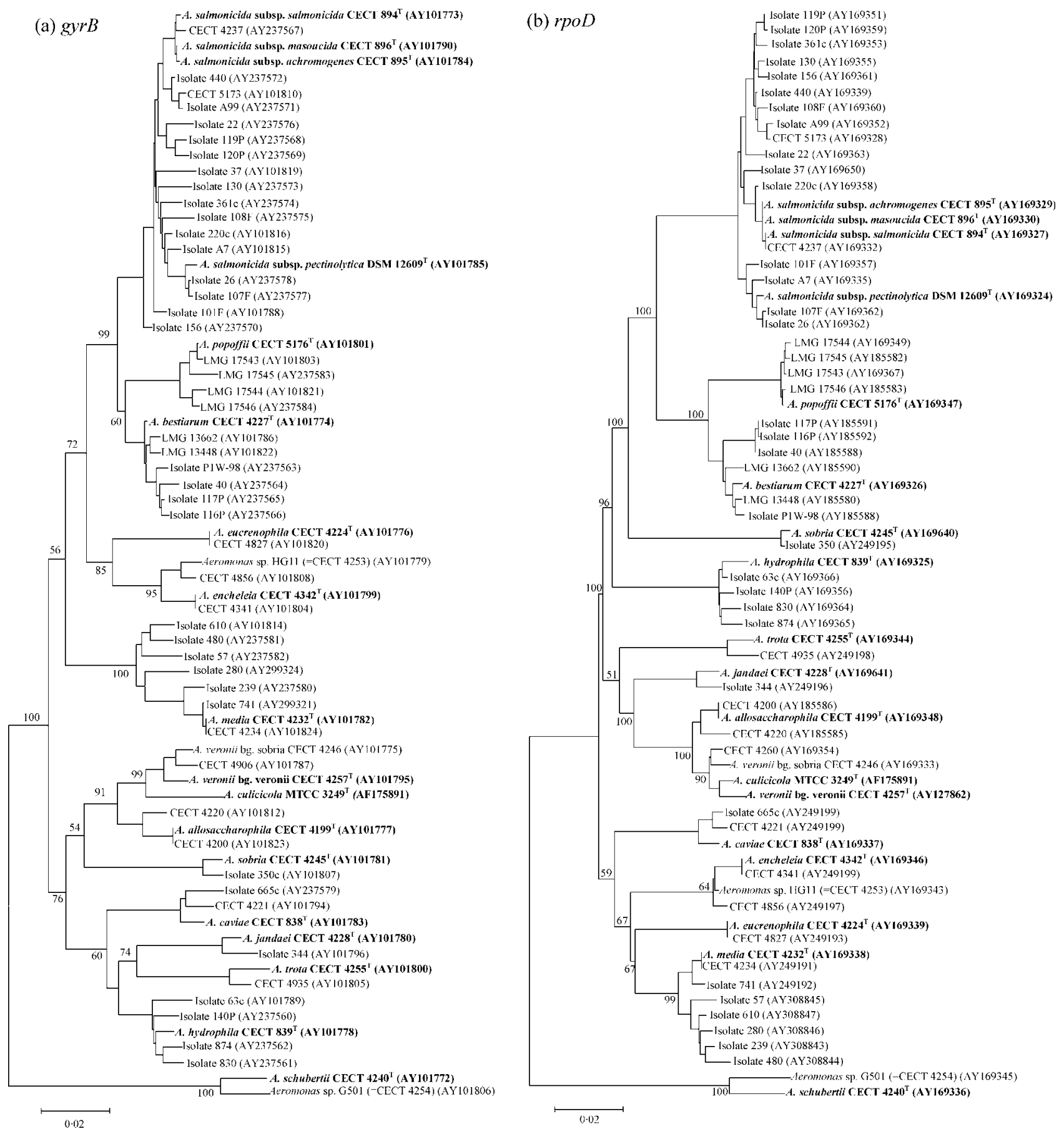

they yielded profiles differing from these corresponding to type strains (Figueras et al., 2000). In the present study, more of those isolates previously selected by 16S rRNA gene-RFLP analysis were included (280, 480, 57, 239 and 741 ), and their $16 \mathrm{~S}$ rRNA, gyrB and $r p o D$ gene sequences were determined. In the gyrB tree (Fig. 1a), the isolates 741 and 239 clustered with the $A$. media type strain, but the rest (isolates 57, 480, 610 and 280), although closely related to A. media, formed an 'independent cluster', indicating that this may represent a distinct phylogenetic line of Aeromonas. Differences in mutations rates were discerned for some of these isolates when comparing gyrB with $r p o D$ sequences, which is why they branched slightly differently in the corresponding trees. An example was isolate 239 which showed a gyrB divergence range of $2 \cdot 9-3.9 \%$ to strains of the above indicated 'independent cluster', but only $1 \cdot 2-1 \cdot 6 \%$ for $r p o D$. This was again a case where different mutational behaviour in two housekeeping genes was found for closely related strains. The possibility of horizontal gene transfer, although not very likely, must be taken into account. Any hypothesis based on these results needs to be supported by a more comprehensive set of gene data. 


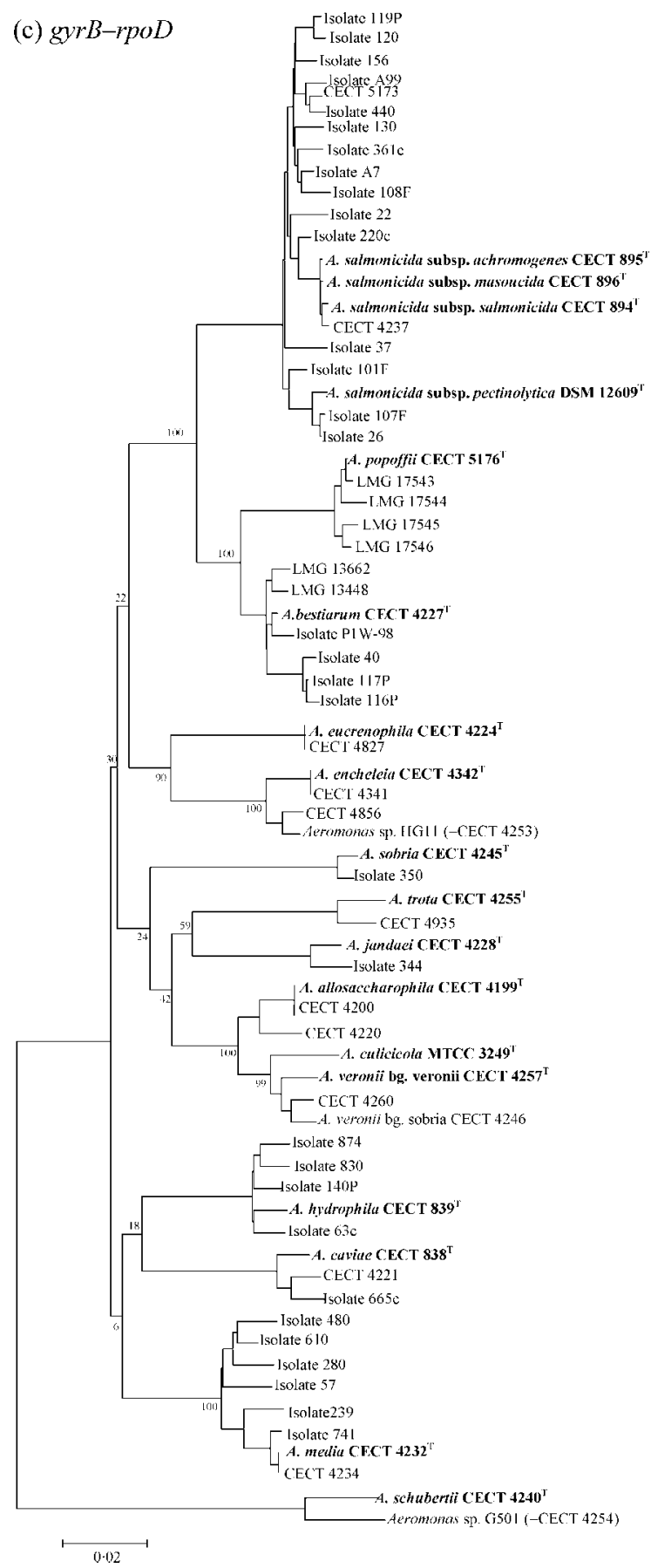

Fig. 1. Unrooted phylogenetic trees based on $\operatorname{gyr} B$ (a), rpoD (b) and the combined stretch of gyrB-rpoD (c) gene sequences, showing relationships in the genus Aeromonas. Type strains are in bold. Numbers shown at nodes indicate bootstrap values (percentage of 1000 replicates). Sequence accession numbers are in parentheses.

\section{The species $A$. salmonicida and $A$. bestiarum}

Our previous gyrB study (Yáñez et al., 2003) showed the inter-relationship between $A$. salmonicida (HG3) and $A$. bestiarum (HG2) as a difficult case to be solved, because a relatively low range of substitutions $(2 \cdot 2-3 \cdot 3 \%)$ was detected. Nevertheless, a limited number of strains was included in the mentioned work. This was consistent with $16 \mathrm{~S}$ rRNA gene studies as, although type strains of these species differ in two single nucleotides (Martínez-Murcia, 1999), many strains simultaneously contained copies of both sequences of $16 \mathrm{~S}$ molecules (present study and unpublished data). Therefore, the presence of one or another sequence of $16 \mathrm{~S}$ rRNA, or both at the same time, seems absolutely random and, as a consequence, splitting A. salmonicida from $A$. bestiarum was not possible by using this genetic marker (Table A in IJSEM Online). All these difficulties were also found in the separation of HG2 from HG3 strains by DNA-DNA hybridization (Ali et al., 1996; Hänninen, 1994). A recent molecular and phenotypic investigation into the taxonomy of the 'A. hydrophila' complex indicated a lack of criteria for splitting $A$. salmonicida from A. bestiarum (unpublished data).

In the present study, the number of strains of these species was greatly increased in an attempt to clarify their phylogenetic relationships. The gyr $B$ inter-species ranges found were $2 \cdot 2-4 \cdot 3 \%$ (between $A$. salmonicida and $A$. bestiarum), $2 \cdot 7-4 \cdot 3 \%$ (A. bestiarum and $A$. popoffii) and $3 \cdot 1-5 \cdot 2 \%$ (A. salmonicida and $A$. popoffii), very low values but still above the overall intra-species ranges observed for Aeromonas. However, the $r p o D$ analysis yielded ranges of $6 \cdot 8-$ $8 \cdot 7,4 \cdot 0-5 \cdot 6$ and $8 \cdot 1-9 \cdot 3 \%$, respectively, indicating that the resolving power to split $A$. salmonicida from $A$. bestiarum was twice that obtained by gyr $B$ sequences. Consequently, we report in this study a phylogenetic marker that was able to separate these two species, not clearly distinguishable by previously used sequences. This is also the advantage of using several housekeeping genes for phylogeny-based systematics (Stackebrandt et al., 2002). Apart from the genetic transfer hypothesis, the study of different genes (obviously not totally synchronized from an evolutionary point of view) may help us to differentiate species more effectively. Whether or not $r p o D$ has been transferred during the evolution of these species should be investigated by sequencing other housekeeping genes.

At the time of submission of this report, a phylogenetic analysis based on gyrB sequences of Aeromonas species appeared (Pidiyar et al., 2003). This study included only type strains and the obtained phylogenetic tree showed notable differences from that published by Yáñez et al. (2003) and from the trees from the present study. We compared the sequence with GenBank/EMBL/DDBJ accession no. AF417635 (Pidiyar et al., 2003) to that with accession no. AY101799 (Yáñez et al., 2003), both obtained from the type strain of $A$. encheleia, and 58 mismatches were found. Moreover, Pidiyar et al. (2003) consider A. veronii biogroup sobria and $A$. veronii biogroup veronii to be different species, which contradicts previous phylogenetic results based on 16S rRNA (Martínez-Murcia et al., 1992), gyrB (Yáñez et al., 2003) and the present work. Our phylogenetic analysis included sequences, checked several 
times, from several strains for each species and the same conclusions were obtained by using two genetic markers, gyrB and $r p o D$.

In conclusion, gyrB and $r p o D$ gene sequences, independently, have proved to be excellent molecular makers for assessing phylogeny in the genus Aeromonas. Moreover, the simultaneous analysis of both clocks improved the reliability and the power to differentiate, in particular, closely related taxa. This advantage derives from the differences in mutation rates that distinct proteins (different functional compromises) contain. Although controversial taxonomic issues remain unsolved, initial evidence for a clear phylogenetic divergence between $A$. salmonicida and A. bestiarum has been shown in this work. The sequences of more genes are obviously needed and may contribute to understanding the evolution of some Aeromonas groups.

\section{ACKNOWLEDGEMENTS}

This work has been supported by grants FIS 99/0944 from the Spanish Ministry of Health, GV98-21-05 from Generalitat Valenciana, Fundació Ciència I Salut, an MIT grant Ministerio de Ciencia y Tecnología for M. A. Y. and a fellowship from the Universitat Rovira i Virgili for L.S. and M.R.C. We would like to thank the Colección Española de Cultivos Tipo (CECT) and the Belgium Co-ordinated Collection of Microorganisms (LMG) for kindly providing isolates. This work was also supported by funds from the European Commission for the AQUA-CHIP project (QLK4-2000-00764).

\section{REFERENCES}

Ali, A., Carnahan, A. M., Altwegg, M., Lüthy-Hottnstein, J. \& Joseph, S. W. (1996). Aeromonas bestiarum sp. nov. (formerly genomospecies DNA group 2 A. hydrophila), a new species isolated from non human sources. Med Microbiol Lett 5, 156-165.

Altwegg, M., Steigerwalt, A. G., Altwegg-Bissig, R., LüthyHottenstein, J. \& Brenner, D. J. (1990). Biochemical identification of Aeromonas genospecies isolated from humans. J Clin Microbiol 28, 258-264.

Austin, D. A., Mclntosh, D. \& Austin, B. (1989). Taxonomy of fish associated Aeromonas spp., with the description of A. salmonicida subsp. smithia nov. Syst Appl Microbiol 11, 277-290.

Barne, K. A., Bown, J. A., Busby, S. J. \& Minchin, S. D. (1997). Region 2.5 of the Escherichia coli RNA polymerase $\sigma^{70}$ subunit is responsible for the recognition of the 'extended-10' motif at promoters. EMBO J 16, 4034-4040.

Carnahan, A. M. (1993). Aeromonas taxonomy: a sea of change. 4th International Workshop on Aeromonas/Plesiomonas, Atlanta, GA. Med Microbiol Newsl 2, 206-211.

Collins, M. D., Martínez-Murcia, A. J. \& Cai, J. (1993). Aeromonas enteropelogenes and Aeromonas ichthiosmia are identical to Aeromonas trota and Aeromonas veronii, respectively, as revealed by smallsubunit rRNA sequence analysis. Int J Syst Bacteriol 43, 855-856.

Figueras, M. J., Soler, L., Chacón, M. R., Guarro, J. \& MartínezMurcia, A. J. (2000). Extended method for discrimination of Aeromonas spp. by $16 \mathrm{~S}$ rDNA RFLP analysis. Int $J$ Syst Evol Microbiol 50, 2069-2073.

Griffin, P. J., Snieszko, S. F. \& Friddle, S. B. (1953). Pigment formation by Bacterium salmonicida. J Bacteriol 65, 652-659.
Gruber, T. M. \& Bryant, D. A. (1997). Molecular systematic studies of eubacteria, using $\sigma^{70}$-type sigma factors of group 1 and group 2 . J Bacteriol 179, 1734-1747.

Hänninen, M. L. (1994). Phenotypic characteristics of the three hybridization groups of Aeromonas hydrophila complex isolated from different sources. J Appl Bacteriol 76, 455-462.

Huang, W. M. (1996). Bacterial diversity based on type II DNA topoisomerase genes. Annu Rev Genet 30, 79-107.

Huys, G., Kämpfer, P., Altwegg, M., Coopman, R., Janssen, P., Gillis, M. \& Kersters, K. (1997). Inclusion of Aeromonas DNA hybridization group 11 in Aeromonas encheleia and extended descriptions of the species Aeromonas eucrenophila and A. encheleia. Int J Syst Bacteriol 47, 1157-1164.

Huys, G., Kämpfer, P. \& Swings, J. (2001). New DNA-DNA hybridization and phenotypic data on the species Aeromonas ichthiosmia and Aeromonas allosaccharophila: A. ichthiosmia Schubert et al. 1990 is a later synonym of A. veronii Hickman-Brenner et al. 1987. Syst Appl Microbiol 24, 177-182.

Huys, G., Denys, R. \& Swings, J. (2002). DNA-DNA reassociation and phenotypic data indicate synonymy between Aeromonas enteropelogenes Schubert et al. 1990 and Aeromonas trota Carnahan et al. 1991. Int J Syst Evol Microbiol 52, 1969-1972.

Janda, J. M. \& Abbott, S. L. (1998). Evolving concepts regarding the genus Aeromonas: an expanding panorama of species, disease presentations, and unanswered questions. Clin Infect Dis 27, 332-344.

Kim, B. J., Lee, S. H., Lyu, M. A., Kim, S. J., Bai, G. H., Chae, G. T., Kim, E. C., Cha, C. Y. \& Kook, Y. H. (1999). Identification of mycobacterial species by comparative sequence analysis of the RNA polymerase gene (rpoB). J Clin Microbiol 37, 1714-1720.

Kimura, M. (1980). A simple method for estimating evolutionary rates of base substitutions through comparative studies of nucleotide sequences. J Mol Evol 16, 111-120.

Kimura, T. (1969a). A new subspecies of Aeromonas salmonicida as an etiological agent of furunculosis on 'sakuramasu' (Oncorhynchus masou) and pink salmon (O. gorbuscha) rearing for maturity. Part 1. On the morphological and physiological properties. Fish Pathol 3, $34-44$.

Kimura, T. (1969b). A new subspecies of Aeromonas salmonicida as an etiological agent of furunculosis on 'sakuramasu' (Oncorhynchus masou) and pink salmon (O. gorbuscha) rearing for maturity. Part 2. On the serological properties. Fish Pathol 3, 45-52.

Kumar, S., Tamura, K., Jakobsen, I. B. \& Nei, M. (2001). MEGA2: Molecular Evolutionary Genetics Analysis software. Bioinformatics 50, 602-612.

Lonetto, M., Gribskow, M. \& Gross, C. A. (1992). The $\sigma^{70}$ family: sequence conservation and evolutionary relationships. J Bacteriol 74, 3843-3849.

Martínez-Murcia, A. J. (1999). Phylogenetic positions of Aeromonas encheleia, Aeromonas popoffi, Aeromonas DNA hybridization group 11 and Aeromonas group 501. Int J Syst Bacteriol 49, 1403-1408.

Martínez-Murcia, A. J., Benlloch, S. \& Collins, M. D. (1992). Phylogenetic interrelationships of members of the genera Aeromonas and Plesiomonas as determined by $16 \mathrm{~S}$ ribosomal DNA sequencing: lack of congruence with results of DNA-DNA hybridizations. Int J Syst Bacteriol 42, 412-421.

Martínez-Murcia, A. J., Antón, A. I. \& Rodríguez-Valera, F. (1999). Patterns of sequence variation in two regions of the 16S rRNA multigene family of Escherichia coli. Int J Syst Bacteriol 49, 601-610.

Pavan, M. E., Abbott, S. L., Zorzópulos, J. \& Janda, J. M. (2000). Aeromonas salmonicida subsp. pectinolytica subsp. nov., a new pectinase-positive subspecies isolated from a heavily polluted river. Int J Syst Evol Microbiol 50, 1119-1124. 
Pidiyar, V., Kaznowski, A., Narayan, N. B., Patole, M. \& Shouche, Y. S. (2002). Aeromonas culicicola sp. nov. (MTC 3249), from the midgut of Culex quinquifasiatus. Int $J$ Syst Evol Microbiol 52, 1723-1728.

Pidiyar, V., Jangid, K., Dayananda, K. M., Kaznowski, A., Gonzales, J. M., Patole, M. \& Shouche, Y. S. (2003). Phylogenetic affiliation of Aeromonas culicicola MTCC $3249^{\mathrm{T}}$ based on gyrB gene sequence and PCR-amplicon sequence analysis of cytolytic enterotoxin gene. Syst Appl Microbiol 26, 197-202.

Saitou, N. \& Nei, M. (1987). The neighbor-joining method: a new method for reconstructing phylogenetic trees. Mol Biol Evol 4, 406-425.

Sawada, H., Suzuki, F., Matsuda, I. \& Saitou, N. (1999). Phylogenetic analysis of Pseudomonas syringae pathovars suggests the horizontal gene transfer of $\operatorname{argK}$ and the evolutionary stability of $h r p$ gene cluster. J Mol Evol 49, 627-644.

Schubert, R. H. W., Hegazi, M. \& Wahlig, W. (1990a). Aeromonas enteropelogenes species nova. Hyg Med 15, 471-472.

Schubert, R. H. W., Hegazi, M. \& Wahlig, W. (1990b). Aeromonas ichthiosmia species nova. Hyg Med 15, 477-479.

Smith, I. W. (1963). The classification of 'Bacterium salmonicida'. J Gen Microbiol 33, 263-274.
Stackebrandt, E., Frederiksen, W., Garrity, G. M. \& 10 other authors (2002). Report of the ad hoc committee for the re-evaluation of the species definition in bacteriology. Int J Syst Evol Microbiol 52, 1043-1047.

Thompson, J. D., Gibson, T. J., Plewniak, F., Jeanmougin, F. \& Higgins, D. G. (1997). The CLUSTAL_X windows interface: flexible strategies for multiple sequence alignment aided by quality analysis tools. Nucleic Acids Res 25, 4876-4882.

Watanabe, K., Nelson, J., Harayama, S. \& Kasai, H. (2001). ICB database: the $\operatorname{gyr} B$ database for identification and classification of bacteria. Nucleic Acids Res 29, 344-345.

Yamamoto, S. \& Harayama, S. (1998). Phylogenetic relationships of Pseudomonas putida strains deduced from the nucleotide sequences of gyrB, rpoD and 16S rRNA genes. Int J Syst Bacteriol 48, 813-819.

Yamamoto, S., Kasai, H., Arnold, D. L., Jackson, R. W., Vivian, A. \& Harayama, S. (2000). Phylogeny of the genus Pseudomonas: intrageneric structure reconstructed from the nucleotide sequences of gyrB and rpoD genes. Microbiology 146, 2385-2394.

Yáñez, M. A., Catalán, V., Apráiz, D., Figueras, M. J. \& MartínezMurcia, A. J. (2003). Phylogenetic analysis of members of the genus Aeromonas based on gyrB gene sequences. Int J Syst Evol Microbiol 53, 875-883. 